\title{
EDITORIAL
}

\section{Formação em saúde no contexto da pandemia da COVID-19: desafios e perspectivas}

0 século XXI tem sido marcado por rápidas transformações demográficas e epidemiológicas; novos riscos infecciosos, ambientais e comportamentais, os quais têm demandado aos sistemas de saúde e aos processos de formação de profissionais de saúde necessidades dinâmicas e complexas. Nesse contexto, a pandemia da COVID-19 trouxe grandes desafios, pois, além de provocar a mais importante crise sanitária dos últimos tempos, vem ocasionando repercussões e crises políticas, sociais, econômicas e culturais sem precedentes na história recente das doenças que acometem a população mundial.

No Brasil, a pandemia tem evidenciado as desigualdades socioeconômicas, colocado em pauta os diversos problemas vivenciados, historicamente, pelos serviços públicos de saúde (Sistema Único de Saúde - SUS) e, acima de tudo, destacado o imprescindível trabalho dos profissionais da área da saúde no enfrentamento da doença e de suas repercussões.

Diante disso, a formação em saúde deve ser repensada, no sentido de atender às necessidades e experiências que o contexto impõe. Mais do que nunca, é preciso estimular e viabilizar uma formação que favoreça a ampliação da concepção de saúde, incorpore a compreensão social dos fenômenos e seus determinantes e possibilite o reconhecimento e a vivência da complexidade da atenção à saúde e da organização dos serviços, a exemplo das Redes de Atenção à Saúde (RAS). Para isso, torna-se fundamental não apenas desenvolver e aprimorar habilidades e competência gerais e específicas descritas nas Diretrizes Curriculares Nacionais (DCN) para formação superior em saúde, como também avançar na perspectiva das competências colaborativas. 0 trabalho em equipe, o compartilhamento, a interdependência, a utilização das Tecnologias de Informação e Comunicação (TIC) e o desenvolvimento de práticas colaborativas se mostram fundamentais para essa discussão.

Para um processo de formação alinhado aos pressupostos do SUS e que responda às diversas demandas apresentadas no contexto da pandemia, a Educação Interprofissional em Saúde (EIP) ganha evidência e amplia as possibilidades para o processo ensino-aprendizagem. A EIP encontra-se alinhada à premissa de que o cuidado em saúde necessita da integração dos profissionais para que seja alcançada a integralidade da assistência. Para isso, a EIP, que é caracterizada por envolver no processo de formação membros de duas ou mais profissões com competências complementares em práticas colaborativas com objetivos comuns, é uma modalidade potente para a transformação das práticas em saúde.

Entretanto, cabe ressaltar que a EIP não se restringe a simplesmente inserir diferentes grupos de estudantes juntos para aprender no mesmo ambiente; é necessário aprender em conjunto, com o propósito explícito de melhorar o trabalho em equipe, a atenção e o cuidado em saúde. Assim, o desenvolvimento de competências colaborativas, na perspectiva do trabalho interprofissional em saúde, exige que as experiências de EIP estejam presentes ao longo da formação dos profissionais. Nesse movimento, destacam-se as atualizações de algumas DCN em saúde que já apontam para esse sentido. Destarte, cabe às Instituições de Ensino Superior (IES) um importante movimento no sentido de revisitar os Projetos Pedagógicos de Curso (PPC) da área da saúde para readequações curriculares dentro dessas perspectivas.

Em consonância com essas necessidades de adequações, e também considerada uma importante estratégia para a "nova" formação em saúde, a incorporação da carga horária específica destinada às atividades de extensão universitária nos PPC (Creditação Curricular da Extensão - Resolução CNE no 7, de 18 de dezembro de 2018) exerce o importante papel de promover a aproximação das IES com a sociedade, fortalecendo a integração ensino-serviçocomunidade na formação dos profissionais de saúde. A Creditação Curricular da Extensão deve estar vinculada a atividades que tenham origem na comunidade externa e que, de alguma 
forma, possam impactar na formação dos estudantes, a partir da interação dialógica da contribuição com a transformação social e do aperfeiçoamento da produção e aplicação do conhecimento, articulando-se sempre com o ensino e a pesquisa.

Embora essas demandas estejam claras e orientem, doravante, as perspectivas para a formação em saúde, sabe-se que ainda existem significativos desafios vigentes impostos pela pandemia atual, os quais necessitam ser contornados no processo de formação em saúde, como o Ensino Remoto Emergencial (ERE). O ERE foi uma estratégia que permitiu, no contexto da pandemia da COVID-19, proporcionar às comunidades acadêmicas a viabilidade de manutenção de atividades relacionadas ao ensino, dentro de circunstâncias possíveis. Contudo, há de se ressaltar que o ERE é uma estratégia temporária, visto que esse método não consegue substituir importantes vínculos necessários entre os distintos atores do processo ensinoaprendizagem na área da saúde, dificultando o desenvolvimento de competências, habilidades e atitudes essenciais para a formação integral dos profissionais.

Pautados os desafios e as perspectivas para a formação em saúde no contexto da pandemia da COVID-19, cabe uma reflexão acerca do papel que cada indivíduo, IES ou serviço de saúde desenvolveu durante o período e o quanto houve, sob uma perspectiva mais otimista, de ganho em termos de aprimoramento tecnológico e pessoal. Os desafios enfrentados, certamente, deixarão algum tipo de marca voltada para a capacidade de superação do que se apresentou a todos.

Quanto aos desdobramentos no período pós-pandemia, apesar de ainda serem, de certo modo, uma incógnita, no campo dos saberes da saúde humana muito foi discutido, repensado e reformulado, o que reflete a incrível capacidade humana de resiliência.

Boa leitura!

Pablo Guilherme Caldarelli

Cirurgião-dentista. Especialista em Ativação de Processos de Mudança na Formação Superior. Mestre em Odontologia em Saúde Coletiva. Doutor em Odontologia. Professor Adjunto na Universidade Estadual de Londrina (UEL) e do Programa de Pós-Graduação em Odontologia da Universidade Positivo.

Marilisa Carneiro Leão Gabardo Cirurgiã-dentista. Especialista em Saúde Coletiva em Odontologia. Mestre e Doutora em Odontologia. Docente do Programa de Pós-Graduação em Odontologia da Universidade Positivo. 